\title{
UN MILAGRO DE ARMONÍAS
}

ALFONSO PÉREZ ROMO

Departamento de Historia/UAA

M. Alejandro Sifuentes Solís, José Luis García Rlvalcaba y Miguel R. Martín del Campo B. Medina, El Camarín de San Diego y su geometría simbólica, Aguascalientes, Universidad Autónoma de Aguascalientes, $1988,208 \mathrm{pp}$.

E n medio del trabajo incesante y tumultuoso; del agobiante bullicio de miles de gentes que transitan, que pregonan, que compran y que venden, que pasan y se quedan; del abigarrado paisaje urbano de un mercado hirviente de actividad; en el cruce de las calles ensordecidas por todos los ruidos, las músicas y las bocinas de automovilistas febricitantes; sostenido por vigorosos contrafuertes y coronado por una cúpula con personalidad y estilo singulares, se levanta el Camarín de San Diego sin que la ingente colmena humana que zumba y se afana en su derredor sospeche siquiera el tesoro de paz, serenidad y armonía espiritual que guarda en su interior.

Es preciso robarle unos minutos al agobio de las prisas y al apremio de una actividad que nos empuja y enajena sin descanso, para darle al espíritu un paréntesis de contemplación y un poco de libertad a los vuelos del alma. Se hace evidente ese deber, que para los hombres de hoy es tan apremiante como apenas ningún otro: el de la contemplación. Nos hemos vuelto activistas y estamos orgullosos de ello; en realidad, hemos dejado de saber callar y concentrarnos, y observar, asumiendo en nosotros lo esencial. También es cierto que nos ha faltado información y guía acerca de nuestros tesoros y nuestras herencias y se nos ha privado de las claves necesarias para comprenderlas. Por eso, a pesar de hablar tanto y tanto de arte, son tan pocos los que tienen una relación auténtica con él. 
El que hoy presentamos es un libro de la más alta delicadeza espiritual porque ha dedicado una atención apasionada a las "formas interiores" de una obra maestra del mundo visible. Es un libro que nos da la llave para conocer los secretos ocultos que son razón de los valores estéticos que conforman la belleza de un monumento tal vez único en nuestro país, reflejo auténtico, sereno, sin rupturas traumáticas, del momento en que un estilo periclita sin morir del todo y le da la mano a otro que llega, como expresión de un mundo que cambia definitivamente.

Sus autores han hecho un trabajo de excepcional importancia, porque han investigado exhaustivamente; porque han sabido penetrar con un método riguroso y con evidente autoridad personal, avalada por su calidad académica, hasta encontrar esa joya escondida que se encuentra en el fondo de toda obra maestra: esa entraña que es marca de origen divino, que cuando se descubre nos hace reconocer que una obra así es buena mas allá de toda comprensión; vemos esto y somos felices, porque comprendemos que ésta es toda la doctrina de la contemplación de la creación terrena.

Cada vez que entramos en el Camarín de San Diego, intuimos de alguna manera que estamos ante un milagro de armonías que nos seducen y nos encantan, sin que nos expliquemos conscientemente su misterio estético.

Desde siempre hemos sabido (no sé si todos los acalitenses que fuera deseable) que poseemos un tesoro arquitectónico único. Sin embargo, ese tesoro ha estado aquí por años y años como una partitura sinfónica de gran aliento en espera de que llegaran nuestros tres autores para interpretarla plenamente en todas sus potencialidades y latencias.

Era necesario hurgar en los viejos archivos históricos, indagar en periódicos y documentos de la época, celebrar innumerables entrevistas y estudiar en detalle la arquitectura regional coetánea, para precisar cuidadosamente las razones y motivos que originaron la construcción del Camarín, su porqué y su cómo.

El último tercio del siglo XVIII es particularmente rico en ideas y sucesos que habrían de transformar radicalmente a todas las sociedades, y Aguascalientes, pequeño rincón de un país a punto de independizarse, no fue ajeno al influjo de esas ideas y de aquellos sucesos. Las ideas de la Ilustración, promovidas por los monarcas borbónicos españoles, apropiadas por nuestros libertadores, despertaron el impulso emancipador como respuesta a la invasión napoleónica de 1808.

Hacía pocos años que había concluido la guerra de independencia de las colo- 
nias inglesas de Norteamérica y en 1789 estalla la Revolución Francesa, que vino a cambiar de tajo las relaciones sociopolíticas en el mundo.

Los nuevos gobernantes no tardaron en apropiarse los símbolos del arte clásico grecoromano que recién habían redescubierto Winckelmann, Lessing y otros. Fue así como estos símbolos pasaron a ser representativos de las nuevas ideas, de la Enciclopedia, de "las luces", de "la razón", tanto como etiquetas distintivas de las nuevas clases gobernantes. El imperio del barroco, con todo lo que representaba y recordaba, estaba condenado a desaparecer.

Sin embargo, en nuestras tierras el ocaso del barroco fue lento, progresivo y tal vez nunca total; la identidad temperamental de los creadores hispanoamericanos con su espíritu, hicieron perdurar el estilo y aún llegaron a darle suaves tintes impregnantes al neoclásico. En las épocas en que el alma humana vive más intensamente, el arte se hace más viviente, pues el arte y el alma se compenetran y se perfeccionan mutuamente. El nexo de los sucesos que brindan las experiencias de la vida también se transforma para devenir acción estética.

Con la notable indagación histórica que nos ofrecen los autores, queda plenamente demostrada la influencia mediata, de Tres Guerras principalmente, tal vez
Tolsá y desde luego la definitiva y directa de Ureña en el diseño y la edificación de la últimas decenas del siglo XviII y aún principios del XIX en toda la región del Bajío. La constatación de similitudes y correspondencias técnicas y estilísticas entre Lagos de Moreno y Aguascalientes, es un rico filón que abre la posibilidad a nuevas e interesantísimas empresas. En lo personal, me parece que entre las fachadas de la Parroquia de Lagos y la de nuestro templo de El Encino, existen suficientes indicios para suponer en algunos detalles huellas de las mismas manos. Si el Camarín de San Diego se inicia recién terminado El Encino, no sería descabellado suponer que Santiago Medina tuvo algo que ver en las dos obras.

Es notable la erudición y justeza de que hacen gala los autores de nuestro libro cuando se ocupan del estudio iconográfico del Camarín La concatenación que encuentran entre las simbologías iconológica y geométrica aporta las luces necesarias para aprehender a plenitud la grandeza del proyecto.

Entre la religión y la música, entre la religión y las artes plásticas, y no hablo sólo del arte primitivo sino del arte de Miguel Angel, de Tintoretto, de Rubens, de Ticiano, de los Bizantinos y románicos, del Abate Suger hasta Le Corbusier, jamás ha cesado de reinar la concordia. 
El estudio iconográfico del Camarín nos permite comprender el ritmo catequético de una rica teología que se armoniza con el ritmo de los números, nos revela una simbología que sigue un hilo conductor que va tejiendo sus ocultas guirnaldas sobre la claridad de la proporción matemática.

Este libro expresa el secreto de las imágenes porque fija en palabras todos sus sentidos expresivos; concreta, así, todo lo que ellos mismos quieren ser y nos quieren decir.

No hay obra hermosa que no dé a primera vista la impresión de haber sido hecha con cierta facilidad, de consistir en la disposición armoniosa pero sencilla de sus partes. Es sólo después de observarla durante largos espacios de tiempo y de estudiarla con detenimiento y método, cuando caemos en cuenta de todo lo que contiene y de la asombrosa complejidad de su composición.

Rima, ritmo, cadencia y estructura -son conceptos que comprende la idea de la forma- no constituyen simples elementos decorativos ni reglas académicas, sino un medio eficaz de prestar el encanto sin el cual toda obra de arte resulta incompleta.

Transformar una masa inerte en una composición que tiene una existencia plástica plena, con masas de dimensiones y secciones diversas unidas por una relación especial, es tarea hija de la inteligencia, del dominio de la técnica, de una buena escuela y de una personalidad altamente sensible y original.

La belleza es objetiva antes de ser subjetiva y, a decir verdad, el grado de subjetividad que interviene en la respuesta del alma, el grado de calor, de profundidad, la intimidad de su respuesta, se hallan en función de la inmutable objetividad del llamado que le ha sido dirigido. El orden es la belleza misma de la belleza.

Es por ello que la parte medular del trabajo de nuestros autores se halla en el descubrimiento de un plan octagónico como estructura esencial que rige el desarrollo estético del edificio. Hay que hacer hincapié en el rigor de los métodos aplicados y la asombrosa concordancia entre los planos espaciales y los planos iconográficos que confirman los resultados del estudio.

Esta admirable descripción nos permite conocer la obra y penetrar profundamente en su comprensión, como si la viéramos nacer desde el parto de su diseño y luego revelándosenos desnuda para que podamos entender la consistencia, el origen y la naturaleza de su belleza en estado puro.

Se ha dicho que el arte no se hace, ni debe hacerse, para que se comprenda, sino para que se sienta; esta es una afirmación incompleta porque siente más íntegramente, más profundamente, con todas las potencias de su ser, quien la conoce y la 
comprende mas íntimamente y mejor. No nos esforzamos para amar, ciertamente; pero amar supone conocer, y para conocer hay que esforzarse. El que mira una obra de arte conversa de alguna manera con el artista por medio del lenguaje del alma; sin embargo, si se conoce además el lenguaje plástico, la comunicación se puede enriquecer todavía más.

El arte refinado no carece de poder si el público es también refinado. Y como el refinamiento sólo llega gracias a la experiencia, a la comparación, a la subordinación de los medios a los fines y al rechazo de lo que estorba, se sigue de ello que una mente refinada posee en realidad la mayor amplitud, así como la discriminación más útil. Su éxtasis sin mueca y su sumisión sin lágrimas mantendrán mejor unidos al cielo y a la tierra -y también mejor separados- de lo que podría lograrlo una imaginación sin cultivo.

Es necesarío decir también que la elaboración de un esquema geométrico compositivo, aunque ciertamente es el elemento básico de cuyas proporciones nace la belleza, no lo es todo; con dos esquemas matemáticamente iguales, dos artistas nos producen dos obras igualmente bellas, semejantes, pero distintas, lo que nos lleva a pensar que la belleza artística es armonía y claridad y unidad de sus partes; pero que hay algo adicional que añade el artista y es lo que da originalidad y carácter único a su obra.

La invención de la forma es algo más que un juego de la fantasía o resultado del dominio de la técnica. Es, ante todo, la manifestación o, más bien, la evocación del espíritu, porque "el alma es la que crea el cuerpo", según la profunda expresión de Leonardo Da Vinci. El arte plástico, pues, al igual que la poesía, es obra mental, psicología en acción, profunda y escudriñadora mirada sobre los misterios del alma, y es algo más que esto, puesto que aspira a rehacer la unidad sintética del ser humano, produciendo la ilusión de la vida íntegra, física y moral a un tiempo, pues la figura corporal, vista y considerada así, no es más que un momento de la vida del espíritu.

Tal vez por eso, Frank Lloyd Wright dijo una vez que ninguna racionalización de la máquina, ni fabricación de la estética, puede oscurecer el hecho de que la arquitectura nace, no se hace, y debe crecer consistentemente desde la intimidad hasta lo que llegue a ser. Las formas que tome deben ser una generación espontánea de los materiales, métodos del diseño, modos de construcción y propósitos.

Un artista es algo más que un niño que mira y ve. Debe comunicar su visión. Su trabajo debe, además, estar presidido por una total serenidad, es decir, no puede 
ser ni opaco ni oscuro, sino manifestarse estremecido por la presencia de la luz. De primera intención uno está tentado de afirmar que ese efecto se logra por medio de la lucidez intelectual. Pero la aseveración resulta incierta; el código de procedimientos civiles del Estado es intelectualmente lúcido, pero aún cuando a nuestros jueces y letrados resulta de utilidad, no es en sí mismo una obra de arte. La finalidad del arte consiste en lograr un nexo de comprensión entre el artista y su público. Si quiere comunicar la totalidad de su visión, debe transmitir no sólo el contenido de la misma, sino también su encanto.

No fue un académico, sino Renoir, quien escribió lo que sigue.

Pero si bien el oficio es la base y lo que presta solidez al arte, no lo es todo. Hay algo más en el arte de nuestros antepasados que determina la belleza de sus producciones: es esa serenidad la que hace que uno jamás se canse de admirarlas y la que nos da una idea de lo que debe ser una obra eterna. Esa serenidad residía en ellos, no solamente a causa de sus vidas simples y tranquilas sino también gracias a su fe religiosa. Se daban perfecta cuenta de sus debilidades y, tanto en sus éxitos como sus fracasos, asociaban sus actos a la divinidad. Dios estaba siempre allí y el hombre no contaba. En la antigua Grecia eran Apolo y Minerva; los pintores de la época de Giotto se colocaron también bajo la advocación de un protector celestial. Precisamente por eso sus obras adquieren ese aspecto de dulce serenidad que les presta un encanto profundo y las hace inmortales.

El libro de los arquitectos Sifuentes, García Ruvalcaba y Martín del Campo nos entrega otro descubrimiento de enorme importancia, nos descubre a un Santiago Medina que se proyecta como hombre y como artista, mucho más alto, mucho más lejos y mucho más hondo, que el modesto alarife que suponíamos un simple ejecutor de las ideas de otros.

Después de leer el admirable trabajo de nuestros autores, la figura de Santiago Medina se agiganta como el autor integral de una obra única, asombrosamente armónica, de finura excepcional y de un difícil pero supremo equilibrio entre un barroco que no acaba de morir y un neoclásico contenido, clarísimo, casi musical.

Un propósito que habría de perseguirse, consistiría en seguir a Santiago Medina hasta encontrarlo del todo; y hacerle merecida justicia pública a este personaje, capaz de encerrar en el espacio de unos cuantos metros y valiéndose de unas pocas piedras toda la poesía, la fe y la voluntad de expresión de un pueblo, en una etapa crucial de su existencia.

El más hermoso esfuerzo de los hombres consiste en cambiar su desorden en orden y la posibilidad en poder; ahí está la verdadera maravilla, que Santiago Medina logró a plenitud.

Termino con una frase de André Malraux: "Ir del signo a la cosa significada es profundizar el mundo, es ir hacia Dios". 